\title{
Uterine Artery Doppler Velocimetry for the Prediction of Preeclampsia among High-risk Pregnancies in Low-resource Setting: Our Experience at Aminu Kano Teaching Hospital, Kano, Nigeria
}

\author{
${ }^{1}$ Murtala Yusuf, ${ }^{2}$ Hadiza Galadanci, ${ }^{3}$ Anas Ismail, ${ }^{4}$ Labaran D Aliyu, ${ }^{5}$ Abdu H Danbatta
}

\section{ABSTRACT}

Several Doppler studies have demonstrated an association between increased impedance to flow in uterine arteries and subsequent development of preeclampsia. This study evaluated the usefulness of uterine artery Doppler velocimetry in the prediction of preeclampsia in high-risk pregnancies.

The study was a prospective cohort study carried out on 138 pregnant women attending antenatal clinic in Aminu Kano Teaching Hospital, a tertiary center in Northern Nigeria. Assessment of uterine artery blood flow by Doppler ultrasound was carried out at 20 to 24 weeks of gestation. The test was considered abnormal when the mean resistance index (RI) in the uterine arteries was $\geq 0.58$ with or without diastolic notch (DN). The women were then followed up to determine those who developed preeclampsia.

The prevalence of preeclampsia in this study was found to be $12.3 \%$. Twenty one of the patients $(15.2 \%)$ had high uterine artery RI $(\geq 0.58)$, while $117(84.8 \%)$ had normal RI $(<0.58)$. The prevalence of preeclampsia was significantly higher $(p<0.05)$ in the group with high RI than in the group with normal RI (57.1 compared with $4.2 \%)$. Nine of the patients $(6.5 \%)$ had DN, while $129(93.5 \%)$ had no DN. The prevalence of preeclampsia was also significantly higher $(p<0.05)$ in the group with $D N$ than in the group with no DN (55 compared with $9.3 \%$ ). Both the sensitivity $(70.5 \%)$ and specificity $(92.6 \%)$ of abnormal $\mathrm{RI}$ in the prediction of preeclampsia were found to be high.

This study confirmed the efficacy of second trimester screening for preeclampsia in high-risk pregnancies using a combination of maternal characteristics and uterine artery Doppler.

Keywords: Doppler ultrasound, Prediction of preeclampsia, Uterine artery.

How to cite this article: Yusuf M, Galadanci H, Ismail A, Aliyu LD, Danbatta AH. Uterine Artery Doppler Velocimetry for the Prediction of Preeclampsia among High-risk Pregnancies in Low-resource Setting: Our Experience at Aminu Kano Teaching Hospital, Kano, Nigeria. Donald School J Ultrasound Obstet Gynecol 2017;11(3):197-202.

\footnotetext{
1,3-5 Consultant, ${ }^{2}$ Professor

1,2,4 Department of Obstetrics and Gynecology, Aminu Kano Teaching Hospital, Kano, Nigeria

${ }^{3,5}$ Department of Radiology, Aminu Kano Teaching Hospital Kano, Nigeria
}

Corresponding Author: Labaran D Aliyu, Consultant Department of Obstetrics and Gynecology, Aminu Kano Teaching Hospital, Kano, Nigeria, Phone: +2348037054199 e-mail: zainalabidinaliyu@yahoo.com

\section{Source of support: Nil}

Conflict of interest: None

\section{INTRODUCTION}

Preeclampsia is a condition that occurs after the 20th week of pregnancy in which hypertension and proteinuria with or without edema are present in a woman who has been previously normotensive. ${ }^{1,2}$ It is one of the most common complications of pregnancy and a cause of high morbidity and mortality for both mother and fetus, especially in developing countries. ${ }^{1-3}$ Without intervention, preeclampsia progresses to eclampsia, which is characterized by hypertension and tonic-clonic convulsions. ${ }^{4}$

The incidence of preeclampsia varies greatly worldwide ranging between 2 and $10 \%$ of pregnancies. ${ }^{5}$ The World Health Organization estimates the incidence of preeclampsia to be seven times higher in developing countries ( $2.8 \%$ of live births) than in developed countries $(0.4 \%)^{5}$

The prevalence of eclampsia in the developed countries is estimated to be about 5 to 7 cases per 10,000 deliveries. On the contrary, prevalence of eclampsia in developing nations varies widely, ranging from 1 case per 100 pregnancies to 1 case per 1,700 pregnancies. ${ }^{6-12}$

Preeclampsia is one of the most important causes of maternal and perinatal morbidity and mortality in both developing and developed countries. ${ }^{13}$

Preeclampsia is characterized by abnormal placental trophoblast invasion in the first and second trimester. Vascular physiological changes occur in the spiral arteries that result in a low-pressure circulation. In those destined to have preeclampsia, those changes do not occur and a high impedance circulation results. ${ }^{15}$ The impedance produced in this circulation may be reflected by increased impedance in either or both uterine arteries. ${ }^{15}$ Doppler velocimetry waveforms of the uterine artery may show a characteristic DN in such circulations. When used at 24 to 26 weeks, Doppler velocimetry waveform analysis using color Doppler ultrasound has produced a sensitivity of $77.3 \%$ and a specificity of $93.9 \%$ in the detection of pregnancy-induced hypertension. ${ }^{16}$ Once the risk 
of developing preeclampsia has been identified, closer antenatal surveillance can be instituted in both mother and the baby. ${ }^{15,17}$

With this in mind, researchers have sought to use ultrasound to identify pregnancies at highest risk for the development of preeclampsia. Most of the studies have been carried out in the Caucasian population with only few in the black population of Africa where the disease is more prevalent and fatal.

The aim of this study is therefore, to evaluate the usefulness of uterine artery Doppler velocimetry in the prediction of preeclampsia in high-risk pregnancies in an African population.

\section{MATERIALS AND METHODS}

The study was carried out in Aminu Kano Teaching Hospital (AKTH), a tertiary health care institution in Northern Nigeria. It was conducted between February 4 and August 5, 2013. It was a prospective cohort study of antenatal women who met the inclusion criteria at booking in the antenatal clinic of AKTH.

The inclusion criteria include all patients with one or more risk factors for preeclampsia who booked for antenatal care in the hospital and consented for the study. Only high-risk pregnant women who booked at a gestational age of $\leq 24$ weeks (based on last menstrual period or early ultrasound sonography) were included. Women without risk factors for preeclampsia were excluded. High-risk pregnant women with gestational age $>24$ weeks as well as women who do not consent for the study were also excluded.

Null hypothesis (H0): Uterine artery Doppler velocimetry is not useful in predicting preeclampsia among high-risk pregnant women.

Alternative hypothesis (H1): Uterine artery Doppler velocimetry is useful in predicting preeclampsia among high-risk pregnant women.

The total number of patients recruited for the study was calculated using the formula:

$$
\begin{gathered}
n=z^{2} \mathrm{pq} / \mathrm{d}^{2} \text { and the prevalence of preeclampsia of } 10 \%{ }^{5} \\
\mathrm{n}=\text { minimum sample size required } \\
\mathrm{z}=\text { standard normal deviate }=1.96 \\
\mathrm{p}=\text { prevalence of the condition in a previous study } / 100=0.1 \\
\mathrm{q}=\text { complimentary probability }=1-\mathrm{p} \\
\mathrm{d}=\text { degree of precision }=0.05 \\
\text { Thus } \mathrm{n}=\frac{1.96^{2}(0.1)(1-0.1)}{(0.05)}=138 \\
\text { Thus, } \mathrm{n}=138
\end{gathered}
$$

This gives a minimum sample size of 138 , which was approximated to 150 by adding $10 \%$ due to attrition.

Data were collected at booking by the principal investigator and trained assistants using a pretested interviewer-administered questionnaire. The purpose of the study was explained to the patient and a written consent form was signed by those willing to participate in the study. Following administration of the questionnaires, ultrasound scan was carried out on the women to determine gestational age, number of fetuses, and fetal biometry.

At 20 to 24 weeks of gestation, the principal researcher together with a consultant radiologist carried out Doppler ultrasonography of the uterine arteries via the transabdominal route on all the women recruited in the study. Doppler flow measurement of the uterine arteries was done using Mindray DC-6, Doppler 6, and a 3.5 MHz convex transducer probe with $100 \mathrm{~Hz}$ filter. The uterine artery will be identified through transabdominal scan on a longitudinal view with a lateral aspect of the lower uterine segment also showing the bifurcation of the common iliac artery. These were identified using color Doppler mode. The recording will be made at the crossing between the uterine and the external iliac arteries as demonstrated using color flow Doppler. Thereafter, the spectral waveform was obtained at an optimal insonating angle of $60^{\circ}$. The Doppler tracing was obtained and recorded by placing a gate of $2.4 \mathrm{~mm}$ (adjusted when necessary) over the artery, utilizing lowest possible filter, and selecting smallest scale that displayed the flow without aliasing. The height of the Doppler waveforms was maximized to facilitate measurement. The pulse repetition frequency for Doppler analysis in this study was set at six samples per second, while the sample volume for pulsed Doppler analysis was $2.4 \mathrm{~mm}$. A trend of at least three similar sequential Doppler waveforms was obtained during suspended respiration. Then the measurement of RI was determined using the internal calipers and analytical software of the sonography unit. The RI was calculated using the formula:

\section{[(Peak systolic frequency shift - Peak diastolic frequency shift)/Peak systolic frequency shift].}

The RI was considered abnormal if $>0.57$. This cutoff value is in accordance with the RI considered abnormal in other published works. ${ }^{18,19}$ At this time, the presence of an early $\mathrm{DN}$ in one or both uterine arteries was also considered.

The women were then divided into two groups: (1) Those with abnormal uterine artery Doppler velocimetry and (2) those with normal velocimetry. They were followed up throughout pregnancy, delivery, and early puerperium. Data on pregnancy outcome were obtained from examination of individual patient notes and labor ward records.

The primary outcome measured was preeclampsia; this requires two recordings of blood pressure of $>140 / 90$ $\mathrm{mm} \mathrm{Hg}$ at least 6 hours apart in a previously normotensive woman, and proteinuria of $300 \mathrm{mg}$ or more in 
24 hours, or two readings of at least + on dipstick analysis of midstream or catheter urine specimens if no 24-hour collection was available. ${ }^{20,21}$ Other outcomes considered include development of eclampsia, mode of delivery, and birth weight of the baby.

The data were analyzed using Epi Info version 3.5 (2008, CDC Atlanta, USA). Quantitative variables were described using mean and standard deviation. Qualitative variables were presented as percentages. Statistical analysis carried out includes chi-squared test.

The predictive power of uterine artery Doppler for preeclampsia was expressed by sensitivity, specificity, positive predictive value (PPV), negative predictive value (NPV), and relative risk (RR) with 95\% confidence interval using two-by-two tables.

An approval for the study was obtained from the Ethical Committee of the hospital.

\section{RESULTS}

In total, 150 consecutive women were recruited for the study, and Doppler examination of the uterine arteries in these women resulted in satisfactory waveforms from both vessels. Complete outcome data were available in 138 women (92\%), and this formed the study population. Preeclampsia occurred in 17 cases (12.3\%), which is consistent with the prevalence of preeclampsia of 2 to $10 \% .^{5}$

The risk factors for preeclampsia in the pregnant women are shown in Table 1. Nulliparity was the commonest risk factor identified in 57 women (41.3\%).

Twenty-one patients (15.2\%) had high uterine artery RI ( $\geq 0.58)$, while 117 (84.8\%) had normal RI $(<0.58)$. Twelve out of the 21 patients with high RI developed preeclampsia, while only 5 out of the 117 patients with normal RI developed preeclampsia (Table 2).

Table 1: Risk factors for preeclampsia

\begin{tabular}{lll}
\hline Risk factors for preeclampsia & Frequency & Percentage \\
\hline Nulliparity & 57 & 41.3 \\
Diabetes mellitus & 8 & 5.8 \\
Chronic renal disease & 2 & 1.4 \\
Chronic hypertension & 13 & 9.5 \\
Previous history & 32 & 23.2 \\
Family history & 13 & 9.5 \\
Multiple gestations & 2 & 1.4 \\
Change of partner & 7 & 5.0 \\
Others & 4 & 2.9 \\
\hline Total & 138 & 100 \\
\hline
\end{tabular}

Table 2: Occurrence of preeclampsia in relation to mean RI

\begin{tabular}{llll}
\hline $\begin{array}{l}\text { Pregnancy } \\
\text { outcome }\end{array}$ & $\begin{array}{l}\text { Normal doppler } \\
(R I<0.58)\end{array}$ & $\begin{array}{l}\text { Abnormal doppler } \\
(R I \geq 0.58)\end{array}$ & Total \\
\hline Preeclampsia & 5 & 12 & 17 \\
No preeclampsia & 112 & 9 & 121 \\
\hline Total & 117 & 21 & 138 \\
\hline
\end{tabular}

The prevalence of preeclampsia was significantly higher $(p<0.05)$ in the group with high RI than in the group with normal RI (57.1 compared with $4.2 \%$ ).

Nine of the patients $(6.5 \%)$ had DN, while $129(93.5 \%)$ had no DN. Five out of the 9 patients with DN developed preeclampsia, while 12 out of the 129 patients with no DN developed preeclampsia (Table 3).

The prevalence of preeclampsia was significantly higher $(\mathrm{p}<0.05)$ in the group with $\mathrm{DN}$ than in the group with no DN (55 compared with 9.3\%).

The incidence of preeclampsia was found to be significantly higher in the group of patients with an abnormal RI value and a DN (83\%) than those with a pathological RI value without a DN (47\%; Table 4).

Table 5 shows the diagnostic indices of an abnormal uterine artery Doppler velocimetry in prediction of preeclampsia among high risk pregnancies. Both the sensitivity (70.5\%) and specificity (92.6\%) of abnormal RI in prediction of preeclampsia was found to be high, though the specificity is higher than the sensitivity. The presence of DN has low sensitivity (55.6\%) but high specificity $(90.7 \%)$ in prediction of preeclampsia.

The presence of high RI of the uterine artery is associated with increased risk of preeclampsia (RR 13; 95\% confidence interval: $0.43-0.74)$ while the presence of DN of the uterine artery is also associated with increased risk of preeclampsia (RR 9; 95\% confidence interval: 0.04-0.09).

Graph 1 shows the modes of delivery in those with abnormal Doppler ( $\mathrm{RI} \geq 0.58$ ) and those with normal Doppler $(\mathrm{RI}<0.58)$. Majority [88 $(77 \%)$ ] of the women with normal Doppler had spontaneous vaginal delivery,

Table 3: Occurrence of preeclampsia in relation to presence of DN

\begin{tabular}{|c|c|c|c|}
\hline $\begin{array}{l}\text { Presence of } \\
\text { preeclampsia }\end{array}$ & $\begin{array}{l}\text { Normal doppler } \\
\text { (absence of DN) }\end{array}$ & $\begin{array}{l}\text { Abnormal doppler } \\
\text { (presence of DN) }\end{array}$ & Total \\
\hline Preeclampsia & 12 & 5 & 17 \\
\hline No preeclampsia & 117 & 4 & 121 \\
\hline Total & 129 & 9 & 138 \\
\hline
\end{tabular}

Table 4: Occurrence of preeclampsia in relation to mean RI and presence of DN

\begin{tabular}{llll}
\hline & $\begin{array}{l}R I \geq 0.58 \\
\text { without DN }\end{array}$ & $\begin{array}{l}R I \geq 0.58 \\
\text { with DN }\end{array}$ & Total \\
\hline Preeclampsia & $7(47 \%)$ & $5(83 \%)$ & 12 \\
No preeclampsia & $8(53 \%)$ & $1(17 \%)$ & 9 \\
\hline Total & $15(100 \%)$ & $6(100 \%)$ & 21 \\
\hline
\end{tabular}

Table 5: Diagnostic indices for prediction of preeclampsia

\begin{tabular}{llllll}
\hline Diagnostic tests & Sens \% & Spec \% & PPV \% & NPV \% & RR \\
\hline $\mathrm{RI} \geq 0.58$ & 70.5 & 92.6 & 57.1 & 95.7 & 13 \\
Presence of DN & 55.6 & 90.7 & 29.4 & 96.7 & 9 \\
\hline
\end{tabular}

Sens: Sensitivity; Spec: Specificity 


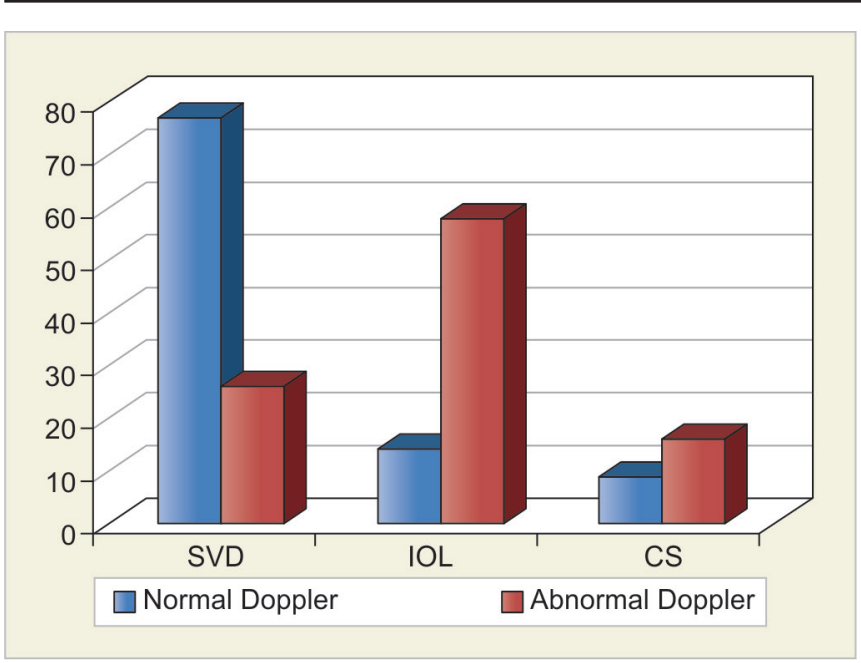

Graph 1: Mode of delivery

while majority of the women [11 (58\%)] with abnormal Doppler had induction of labor.

Graph 2 shows the distribution of birth weight in both groups. The prevalence of low birth weight is higher in those with high RI (26.3\%) compared with those with normal RI (22.4\%).

\section{DISCUSSION}

Doppler velocimetry of uterine arteries in the second trimester is a reliable and useful tool in predicting preeclampsia. 18,19 There are a lot of studies that evaluated the usefulness of uterine artery Doppler velocimetry in the prediction of preeclampsia; however, only few studies have analyzed the predictive role of uterine artery Doppler velocimetry in high-risk pregnancies. ${ }^{18,19,22}$ Most of the studies on the predictive role of uterine artery Doppler velocimetry for preeclampsia were on unselected populations. ${ }^{23-28}$ Different velocimetry indices have been used to define abnormal Doppler in various studies. In this study, abnormal Doppler was defined as presence of high RI $(\geq 0.58)$ with or without DN. This cutoff value is in accordance with the RI considered abnormal in other published works. ${ }^{18,19}$ Twenty one of the patients (15.2\%) had abnormal Doppler, while $84.8 \%$ had normal Doppler. In this study, the prevalence of preeclampsia was significantly higher $(\mathrm{p}<0.05)$ in the group with high RI than in the group with normal RI. The presence of high RI was thus found to be predictive of preeclampsia in high-risk pregnancies. All the diagnostic indices were found to be high: The sensitivity $(70.5 \%)$, specificity $(92.6 \%)$, PPV (57.1), and NPV (95.7). The high sensitivity and specificity recorded in this study is similar to what was obtained by Arduini et al, ${ }^{18}$ Jacobson et al, ${ }_{1}^{19}$ and Zimmerman et al. ${ }^{22}$ This is because those studies were also carried out on selected populations. However, the sensitivity and specificity reported in this study were higher than those

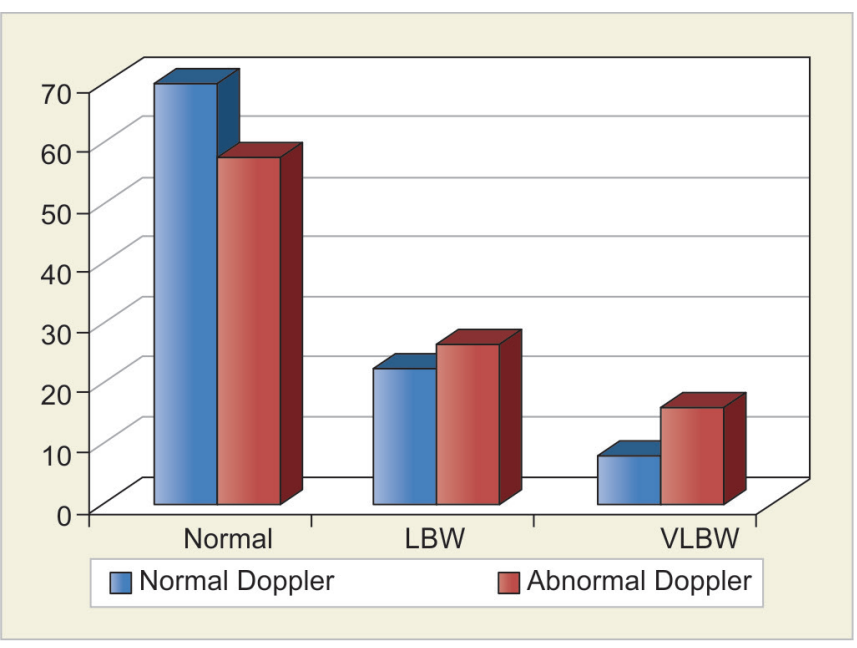

Graph 2: Distribution of birth weight

Table 6: Diagnostic indices in selected and unselected populations

\begin{tabular}{lccccc}
\hline & $\begin{array}{l}\text { Prev } \\
\%\end{array}$ & $\begin{array}{l}\text { Sens } \\
\%\end{array}$ & $\begin{array}{l}\text { Spec } \\
\%\end{array}$ & $\begin{array}{l}\text { PPV } \\
\%\end{array}$ & $\begin{array}{l}\text { NPV } \\
\%\end{array}$ \\
\hline Selected populations & & & & & \\
This study & 12 & 71 & 93 & 57 & 96 \\
Arduini et al $^{18}$ & 37 & 64 & 94 & 70 & 80 \\
Jacobson et al $^{19}$ & 29 & 44 & 73 & 33 & 81 \\
Zimmerman et al $^{22}$ & 18 & 56 & 83 & 43 & 89 \\
Unselected populations $^{22}$ & & & & & \\
This study $_{\text {Bewley et al }}^{23}$ & 12 & 71 & 93 & 57 & 96 \\
Steel et al $^{25}$ & 4.6 & 24 & 95 & 20 & 96 \\
Albaiges et al $^{27}$ & 1.9 & 63 & 89 & 10 & 99 \\
\hline
\end{tabular}

found in studies carried out on unselected populations (Table 6). ${ }^{23,25,27}$

The presence of DN can also be used to define abnormal Doppler velocimetry. Diastolic notch was present in $29.4 \%$ of the patients who subsequently developed preeclampsia in this study. In those who did not develop preeclampsia, only $3.3 \%$ had DN. This is also similar to the findings of Zimmerman et $\mathrm{al}^{22}$ in which $31.3 \%$ of the women with bilateral notches developed preeclampsia, while only $9.9 \%$ of those with normal outcome had DN. This is also in agreement with the findings of Jacobson et $\mathrm{al}^{19}$ and Arduini et al. ${ }^{18}$ The prevalence of preeclampsia was found to be significantly higher in the group with DN than in the group with no DN. The presence of DN alone, however, has low sensitivity (55.6\%) but high specificity $(90.7 \%)$ in predicting preeclampsia.

The inclusion of DN to high RI in the definition of abnormal velocimetry improves the prediction of preeclampsia. ${ }^{16,23}$ We also agree with the importance of introducing early DN to improve the predictive value of uterine artery Doppler velocimetry, this is because we found that the incidence of preeclampsia was significantly higher in the group of patients with an abnormal RI value 
and a DN (83\%) compared with those with a pathological RI value only without a DN (47\%).

In this study, the pregnancy outcome was found to be more favorable in those with normal Doppler, this is because the prevalence of low birth weight was higher in those with abnormal Doppler compared with those with normal Doppler.

The strength of this study is that it was performed among high-risk pregnant women who have risk factors for preeclampsia unlike other studies that were conducted among unselected population. The limitation for the study is that the Doppler ultrasound was done via the abdominal route, instead of transvaginal route; this was because of the cultural and religious sensitivity of the study population. However, to ensure accuracy of the Doppler ultrasound, the Doppler ultrasound scans were done via transabdominal route at the iliac fossae, using similar settings and machine. All sonographic examinations were done by the same consultant radiologist, who is one of the authors of the manuscript with more than 10 years of experience in vascular ultrasound.

It has been demonstrated from this study and other similar studies that the best prediction of preeclampsia is provided by combining risk factors in the maternal history with Doppler assessment of the uterine arteries. The aim of this prediction is to help stratify the antenatal women so as to intensify subsequent surveillance. Although there is the potential anxiety associated with being classified as a high risk for preeclampsia, such a classification does not carry a direct risk to the mother or the fetus. ${ }^{28}$ Uterine artery Doppler velocimetry can, therefore, be employed clinically among high-risk pregnant women to predict those who are likely to have preeclampsia. Those patients can then be monitored more frequently, especially in low-resource countries where the number of antenatal patients is large. The patients can also be offered preventive measures, such as low-dose aspirin during the pregnancy.

\section{CONCLUSION}

In conclusion, our data confirmed the efficacy of second trimester screening for preeclampsia in high-risk pregnancies using a combination of maternal characteristics and uterine artery Doppler. The presence of high RI of the uterine artery and/or the appearance of DN is associated with an increased risk of development of preeclampsia. We therefore, recommend the introduction of this technique into routine antenatal care for high-risk pregnancies.

\section{REFERENCES}

1. Emuveyan E. Pregnancy induced hypertension. Trop J Obstet Gynaecol 1995;12(1):8-11.
2. Itam HI, Ekabule JE. A review of pregnancy outcome in women with eclampsia at the University of Calabar Teaching Hospital, Calabar. Trop J Obstet Gynaecol 2002;18(2):66-68.

3. Vanderjagt DJ, Patel RJ, El-Nafaty AU, Melah GS, Crossey MJ, Glew RH. High-density lipoprotein and homocysteine levels correlate inversely in preeclamptic women in northern Nigeria. Acta Obstet Gynaecol Scand 2004 Jun;83(6): 536-542.

4. Packer CS. Biochemical markers and physiological parameters as indices for identifying patients at risk of developing preeclampsia. J Hypertens 2005 Jan;23(1):45-46.

5. Dolea, C.; AbouZahr, C. Global burden of hypertensive disorders of pregnancy in the year 2000. Global Burden of Diseases 2000 Working Paper. Geneva: World Health Organization; 2003.

6. Shah, AK. Preeclampsia and Eclampsia. 2009. [cited 2011 Mar 8]. Available from: http://emedicine.medscape.com/ article/1184270-overview.

7. WHO. Coverage of maternity care: a listing of available information. Geneva: World Health Organization; 2004.

8. Kimbally KG, Barassoumbi H, Buambo SF, Gombet T, KibekeP, Monabeka HG, Iloki LH, Ekoundzola JR. Arterial hypertension: epidemiological aspects and risk factors on pregnant and delivered woman. Dakar Méd 2007;52(2):148-152.

9. Teklu S, Gaym A. Prevalence and clinical correlates of the hypertensive disorders of pregnancy at Tikur Anbessa Hospital, Addis Ababa, Ethiopia. Ethiop Med J 2006 Jan;44(1): 17-26.

10. Omole-Ohonsi A, Ashimi AO. Pre-eclampsia: a study of risk factors. Niger Med Pract 2008;53(6):99-102.

11. Olopade FE, Lawoyin TO. Maternal mortality in a Nigerian Maternity Hospital. Afr J Biomed Res 2008 Sep;11(3):267-273.

12. Population Council Nigeria. Administering magnesium sulfate to treat severe pre-eclampsia and eclampsia. 2009. [cited 2011 May 16]. Available from: http:/ / www.popcouncil. org/projects/134AdminMagSulfPreeclampsia.asp.

13. Duley L. Maternal mortality associated with hypertensive disorders of pregnancy in Africa, Asia, Latin America and the Caribbean. Br J Obstet Gynaecol 1992 Jul;99(7):547-553.

14. World Health Organization. The World Health Report 1998. Life in the 21st century: a vision for all. Geneva: WHO; 1998. p. 97.

15. Repke JT, Robinson JN. The prevention and management of pre-eclampsia and eclampsia. Int J Gynaecol Obstet 1998 Jul;62(1):1-9.

16. Harrington $\mathrm{K}$, Cooper D, Lees C, Hecher K, Campbell S. Doppler ultrasound of the uterine arteries: the importance of bilateral notching in the prediction of preeclampsia, placental abruption or delivery of a small for gestational age baby. Ultrasound Obstet Gynaecol 1996 Mar;7(3):182-188.

17. Roberts JM, Pearson G, Cutler J, Lindheimer M. Summary of the NHLBI working group on research on hypertension during pregnancy. Hypertension 2003 Mar;41:437-445.

18. Arduini D, Rizzo G, Romanini C, Mancuso S. Utero-placental blood flow velocity waveforms as predictors of pregnancy induced hypertension. Eur J Obstet Gynecol Reprod Biol 1987 Dec;26(4):335-341.

19. Jacobson SL, Imhof R, Manning N, Mannion V, Little D, Rey E, Redman C. The value of Doppler assessment of the uteroplacental circulation in predicting preeclampsia or intrauterine growth retardation. Am J Obstet Gynecol 1990 Jan;162(1): 110-114. 
20. Sibai BM. Diagnosis and management of gestational hypertension and preeclampsia. Obstet Gynaecol 2003 Jul;102(1):181-192.

21. Hauth JC, Ewell MG, Levine RL, Esterlitz JR, Sibai B, Curet LB, Catalano PM, Morris CD. Pregnancy outcomes in healthy nullipara women who subsequently developed hypertension. Obstet Gynaecol 2000 Jan;95(1):24-28.

22. Zimmerman P, Eirio V, Kosinen J, Kujansuu E, Ranta T. Doppler assessment of the uterine and uteroplacental circulation in the second trimester in pregnancies at high risk for preeclampsia and/or intrauterine growth retardation: comparison and correlation between different Doppler parameters. Ultrasound Obstet Gynecol 1997 May;9(5):330-338.

23. Bewley S, Cooper D, Campbell S. Doppler investigation of uteroplacental blood flow resistance in the second trimester: a screening study for pre-eclampsia and intrauterine growth retardation. Br J Obstet Gynaecol 1991 Sep;98(9):871-879.

24. Bower S, Schuchter K, Campbell S. Doppler ultrasound screening as part of routine antenatal scanning: prediction of pre-eclampsia and intrauterine growth retardation. Br J Obstet Gynaecol 1993 Nov;100(11):989-994.

25. Steel SA, Pearce JM, McParland P, Chamberlain GV. Early Doppler ultrasound screening in prediction of hypertensive disorders of pregnancy. Lancet 1990 Jun;335(8705):1548-1551.

26. Bower S, Bewley S, Campbell S. Improved prediction of preeclampsia by two-stage screening of uterine arteries using the early diastolic notch and color Doppler imaging. Obstet Gynecol 1993 Jul;82(1):78-83.

27. Albaiges G,Missfelder-LobosH,LeesC,Parra M,Nicolaides KH. One-stage screening for pregnancy complications by color Doppler assessment of the uterine arteries at 23 weeks' gestation. Obstet Gynecol 2000 Oct;96(4):559-564.

28. Papageorghiou AT, Yu CK, Bindra R, Pandis G, Nicolaides KH, Fetal Medicine Foundation Second Trimester Screening Group. Multicenter screening for pre-eclampsia and fetal growth restriction by transvaginal uterine artery Doppler at 23 weeks of gestation. Ultrasound Obstet Gynecol 2001 Nov;18(5):441-449. 